\title{
Corrigendum: Detection of a Novel DSPP Mutation by NGS in a Population Isolate in Madagascar
}

\begin{abstract}
Agnès Bloch-Zupan ${ }^{1,2,3 *}$, Mathilde Huckert',4, Corinne Stoetzel', Julia Meyer ${ }^{1}$, Véronique Geoffroy ${ }^{4}$, Rabisoa W. Razafindrakoto ${ }^{5}$, Saholy N. Ralison ${ }^{5}$, Jean-Claude Randrianaivo ${ }^{5}$, Georgette Ralison ${ }^{5}$, Rija O. Andriamasinoro ${ }^{5}$, Rija H. Ramanampamaharana ${ }^{5}$, Solofomanantsoa E. Randrianazary ${ }^{5}$, Louise H. Ralimanana ${ }^{5}$, Béatrice Richard ${ }^{6}$, Philippe Gorry ${ }^{7}$, Marie-Cécile Manière ${ }^{1,2}$, Jeanne A. Rasoamananjara ${ }^{5}$, Simone Rakoto Alson ${ }^{5}$ and Hélène Dollfus ${ }^{4}$

${ }^{1}$ Faculté de Chirurgie Dentaire, Université de Strasbourg, Strasbourg, France, ${ }^{2}$ Centre de Référence des Manifestations Odontologiques des Maladies Rares, Hôpitaux Universitaires de Strasbourg, Pôle de Médecine et Chirurgie Bucco-dentaires Hôpital Civil, Strasbourg, France, ${ }^{3}$ Centre National de la Recherche Scientifique-UMR7104, Institut de Génétique et de Biologie Moléculaire et Cellulaire, Institut National de la Santé et de la Recherche Médicale U 964, Université de Strasbourg, IIlkirch, France, ${ }^{4}$ Laboratoire de Génétique Médicale, Faculté de Médecine, Institut National de la Santé et de la Recherche Médicale U 1112, Université de Strasbourg, Strasbourg, France, ${ }^{5}$ Institut d'Odonto-Stomatologie Tropicale de Madagascar, Université de Mahajanga, Mahajanga, Madagascar, ${ }^{6}$ UFR Odontologie de Lyon, Université Claude Bernard, Lyon, France, ${ }^{7}$ Research Unit of Theoretical \& Applied Economics, GREThA (UMR Centre National de la Recherche Scientifique 5113), Université de Bordeaux Pessac, Pessac, France
\end{abstract}

Keywords: rare disease, dentinogenesis imperfecta, dental anomalies, dentin, mutation, NGS, humans

\section{OPEN ACCESS}

Edited and reviewed by: Thimios Mitsiadis, University of Zurich, Switzerland

${ }^{*}$ Correspondence: Agnès Bloch-Zupan agnes.bloch-zupan@unistra.fr

Specialty section: This article was submitted to Craniofacial Biology, a section of the journal Frontiers in Physiology

Received: 10 May 2016 Accepted: 06 July 2016 Published: 26 July 2016

Citation:

Bloch-Zupan A, Huckert M Stoetzel C, Meyer J, Geoffroy V, Razafindrakoto $R W$, Ralison $S N$,

Randrianaivo J-C, Ralison G, Andriamasinoro $R O$,

Ramanampamaharana $\mathrm{RH}$ Randrianazary SE, Ralimanana $L H$, Richard B, Gorry P, Manière M-C, Rasoamananjara JA, Rakoto Alson S and Dollfus H (2016) Corrigendum: Detection of a Novel DSPP Mutation by NGS in a Population Isolate in Madagascar. Front. Physiol. 7:304. doi: 10.3389/fphys.2016.00304

\section{A corrigendum on}

Detection of a Novel DSPP Mutation by NGS in a Population Isolate in Madagascar by Bloch-Zupan, A., Huckert, M., Stoetzel, C., Meyer, J., Geoffroy, V., Razafindrakoto, R. W., et al. (2016). Front. Physiol. 7:70. doi: 10.3389/fphys.2016.00070

Reason for Corrigendum:

The authors, Jeanne A. Rasoamananjara and Louise H. Ralimanana were inadvertently missed in the original manuscript and we wish to add their names for contribution to this work. All authors have agreed to this modification.

The authors apologize for this oversight. This error does not change the scientific conclusions of the article in any way.

The original article has been updated.

\section{AUTHOR CONTRIBUTIONS}

ABZ, MH, CS, JM, VG, RWR, SNR, JCR, GR, ROA, RHR, SER, LHR, BR, PG, MCM, JAR, SRA and HD approved the content of Corrigendum.

Conflict of Interest Statement: The authors declare that the research was conducted in the absence of any commercial or financial relationships that could be construed as a potential conflict of interest.

Copyright (c) 2016 Bloch-Zupan, Huckert, Stoetzel, Meyer, Geoffroy, Razafindrakoto, Ralison, Randrianaivo, Ralison, Andriamasinoro, Ramanampamaharana, Randrianazary, Ralimanana, Richard, Gorry, Manière, Rasoamananjara, Rakoto Alson and Dollfus. This is an open-access article distributed under the terms of the Creative Commons Attribution License (CC BY). The use, distribution or reproduction in other forums is permitted, provided the original author(s) or licensor are credited and that the original publication in this journal is cited, in accordance with accepted academic practice. No use, distribution or reproduction is permitted which does not comply with these terms. 